\title{
$O$ conceito de paisagem no tempo
}

Ilana Kiyotani*

\section{Resumo}

O conceito de paisagem pensado desde a Modernidade, através do entendimento pelo senso comum, passou ao longo dos anos por várias reflexões e modificações. O termo que apareceu pela primeira vez em língua alemã (Landschaft) foi traduzido para várias línguas e ganhou o mundo, tornando-se um dos mais estudados entre várias ciências e profissões. Sempre designado como um recorte do espaço captado pelo olhar do observador, o conceito foi agregando com o tempo um olhar mais sensível; a paisagem deixou de ser apenas um fragmento do espaço físico para conceber-se como cultura, como a realidade de várias interrelações entre seres e meio visíveis ou não aos nossos olhos. Propõe-se neste artigo percorrer esse trajeto do conceito de paisagem no tempo, dando ênfase a como ele se desenvolveu na ciência geográfica.

Palavras-chave: Paisagem; Geografia; Epistemologia; Ciência.

The concept of landscape in time

\begin{abstract}
The concept of landscape thought since antiquity, by understanding the common sense, has over the years by various reflections and modifications until the present day. The term first appeared in German (Landschaft) was translated into several languages and won the world, becoming one of the most studied, among various sciences and professions. When designated as an approach to the space captured by the eye of the beholder, the concept was taken
\end{abstract}

Universidade Federal de Pernambuco (ilana.kiyotani@gmail.com).

Geosul, Florianópolis, v. 29, n. 57, p 27-42, jan.jun. 2014 
KIYOTANI, I. O conceito de paisagem no tempo.

up by the time a more sensitive, the landscape is no longer just a fragment of the physical space to be conceived as a culture, as the reality of the interplay between various beings and the environment visible or not to our eyes. It is proposed in this article path through the concept of landscape in time, emphasizing how it developed in geographical science.

Key words: Landscape; Geography; Epistemology; Science.

O conceito de paisagem é ainda hoje um campo do conhecimento que passa por questionamentos. Ao longo dos anos, desde a Modernidade, este conceito sendo formado por vários ramos do conhecimento, seja por pintores, filósofos, literários, geógrafos, arquitetos, ambientalistas; enfim, uma infinidade de "definições" e principalmente de percepções surgiram para tentar defini-lo.

Este breve estudo tem por objetivo resgatar algumas das percepções surgidas ao longo do tempo, analisando sua evolução, porém sem a pretensão de abranger todos os momentos de discussão, já que "paisagem" teve e tem um grande número de definições e estudos. Aqui seguirão momentos nos quais a mudança na percepção da paisagem foi mais marcante, dando ênfase a sua construção dentro da ciência geográfica.

"Até o século XVIII, a paisagem era sinônimo de pintura. Assim, foi na mediação com a arte que o sítio (lugar) adquiriu estatuto de paisagem" (ROSENDAHL e CORRÊA, p.15, 2001). Estas imagens pintadas pelos artistas eram o que dava definição ao termo paisagem. Até o século XIV as paisagens estavam presentes apenas como fundo para quadros religiosos, cenas do dia-a-dia ou retratos, foi a partir do século XV que elas passaram a ser, de fato, o propósito primordial da pintura (ALVES, 2001, p.68).

A paisagem neste tempo se dá como a exibição de cenas da natureza que atendem aos valores estéticos dos seus observadores, não é algo que se comprometa com a realidade vivida ou as condições de vida, são apenas ideais de beleza que são pintados 
KIYOTANI, I. O conceito de paisagem no tempo.

para serem admirados, contemplados. É justamente a natureza contemplativa que a princípio trará a noção de paisagem à tona.

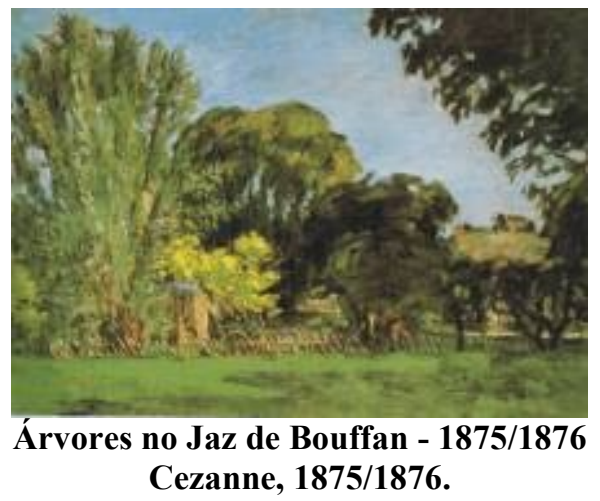

Para quê descrições quando o olhar depara-se com um quadro como este de Cézanne (1875/1876), a imagem é bem clara, porém o sentido dela provavelmente irá mudar de acordo com o mundo interior de cada contemplador. Aparentemente tudo que um artista quer expressar está em sua obra, por isso que a paisagem é simbologia e semiótica, é a forma do autor expor seu olhar e tentar fazer com que o outro o capture; ou quem sabe, despertar um novo olhar a cada observador que surgir.

Paisagem tem a ver com sentimento, com a visão interior que cada ser tem de si mesmo, ou do lugar que vive, ou dos sonhos que possui; ela não é absoluta como uma soma matemática, senão uma soma de sentimentos enraizados nos que a reproduz e nos que a observa. Em outros domínios das artes como a música ou a literatura a paisagem foi também forma de afirmação identitária, onde cada ser pode agarra-se as suas origens, lembrando-a, sentindo-a, seja lendo, compondo, ouvindo.

Tantos foram os poetas, literários, músicos que escreveram e cantaram paisagens. Alguns de forma extremamente descritiva, como se detalhasse uma foto, outros utilizando metáforas, prosopopeias, para dar vida ao sentimento. Abaixo o poeta 
KIYOTANI, I. O conceito de paisagem no tempo.

português Fernando Pessoa define o que é para ele paisagem, quem sabe é este um "conceito poético",

\section{Paisagens, quero-as comigo ${ }^{1}$}

Paisagens, quero-as comigo.

Paisagens, quadros que são...

Ondular louro do trigo,

Faróis de sóis que sigo,

Céu mau, juncos, solidão...

Umas pela mão de Deus,

Outras pelas mãos das fadas,

Outras por acasos meus,

Outras por lembranças dadas...

Paisagens... Recordações,

Porque até o que se vê

Com primeiras impressões

Algures foi o que é,

No ciclo das sensações.

Paisagens... Enfim, o teor

Da que está aqui é a rua

Onde ao sol bom do torpor

Que na alma se me insinua

Não vejo nada melhor.

A partir da exposição da paisagem pelos artistas começa-se a construir uma definição para o termo sob o senso comum. Ora, o que se vê de belo, do natural, é paisagem; é aquele lugar, aquela visão, que o observador pode avaliar como harmônico e esteticamente bonito. Diferente da ciência, a percepção da paisagem no senso comum não avalia elementos ou graus qualitativos, a paisagem torna-se simplesmente feia ou bonita.

Em linha epistemológica, uma ruptura entre o senso comum e a ciência dá-se na transição da ciência clássica para a ciência

${ }^{1}$ Disponível em: http://www.revista.agulha.nom.br/fpessoa262.html. Acesso: 03/08/2010. 
KIYOTANI, I. O conceito de paisagem no tempo.

moderna. Se na ciência clássica o subjetivismo é enfatizado, a busca é pessoal e voltada para questões de bem-estar, no conhecimento moderno o saber é imparcial. Segundo Santos (1989, p. 33),

"em ciência, nada é dado, tudo se constrói. O senso comum, o conhecimento vulgar (...) são opiniões, formas de conhecimento falso com que é preciso romper para que se torne possível o conhecimento científico, racional e válido. A ciência constrói-se pois contra o senso comum e, para isso, dispões de três atos epistemológicos fundamentais: a ruptura, a construção e a constatação".

Desta mesma forma acontecerá com o conceito de paisagem, o que antes somente esteve presente no senso comum começa ser construído dentro de algumas ciências. Segundo Tricard (1982, p. 15)

"a noção de paisagem diferencia-se desde então, do senso comum do termo. Este permanece puramente descritivo e vago, pois que não existe necessidade de precisar na paisagem os elementos que a constituem. Paisagem pode descrever um conteúdo emotivo, estético, intrinsecamente subjetivo do próprio fato. Ao contrário, o conceito cientifico de paisagem abrange uma realidade que reflete as profundas relações, frequentemente não visíveis, entre seus elementos. A pesquisa dessas relações é um tema de investigação regidas pelo método cientifico. (...) a paisagem, na concepção vulgar do termo, nada mais é do que a ponta do iceberg. Ao pesquisador, cabe estudar toda a parte escondida para compreender a parte revelada".

Mais especificamente dentro da geografia, ciência aqui enfatizada, este conceito sofrerá rupturas, a principal delas virá com a Geografia Crítica, onde toma-se um olhar mais humanista para estudá-lo. A geografia desde sua iniciação como disciplina científica, vem estudando a paisagem, aliás, foi justamente este 
KIYOTANI, I. O conceito de paisagem no tempo.

conceito um dos primeiros a ser sustentáculo desta ciência, desde Humboldt e Ritter.

"Na herança da estética romântica naturalista, bem evidenciada por Humboldt, a paisagem ocupa lugar proeminente na Geografia. (...) Com efeito, landschaf tanto significava uma porção limitada da superfície da terra que possuía um ou mais elementos que lhe davam unidade, como a aparência da terra tal como era percebida por um observador." (SALGUEIRO, 2001, p. 40)

Segundo Salgueiro (2001), neste primeiro momento existiu dois principais modos de se estudar a paisagem pela geografia: um baseado na fisionomia e outro que expressa além dos seus atributos físicos-naturais e humanos, as interligações entre tais.

De fato, primeiramente, na geografia, se analisou a paisagem muito mais sob sua perspectiva puramente física do que aquela humanizada. Desse momento surgiram inúmeros trabalhos descritivos, que se atinham a detalhes topográficos e geomorfológicos. Faziam parte desses estudos a observação do relevo, vegetação, solo e clima. Segundo Tricart (1982), para os brasileiros, relevo e solo, se constituem em características determinantes para o estudo da paisagem. Christofoletti ${ }^{3}$ em 1982, fazendo um apanhado sobre a ciência geográfica acrescenta,

${ }^{2}$ Landschaft significa paisagem em Alemão, primeira língua a utilizar e conceituar o termo que hoje conhecemos. Segundo Tricard (1982), landschaft é um termo erudito utilizado principalmente pelos geógrafos. Em seu artigo Paisagem e Ecologia, o autor complementa: "os estudiosos alemães da Geografia Física utilizavam corretamente o termo 'Landschaft'. Para os geógrafos alemães, geralmente nutridos de ciências naturais, a paisagem compõe-se de diversos elementos concretos do ambiente: relevo, planta, solos. Mas eles não registram as modificações introduzidas pelo homem e, se for o caso, eles distinguem entre a paisagem natural e a paisagem humanizada". (TRICARD, 1982, p. 13)

${ }^{3}$ CHRISTOFOLETTI, Antonio. As Características da Nova Geografia. In: (org). Perspectivas da Geografia. São Paulo: Difel, 1982. 
KIYOTANI, I. O conceito de paisagem no tempo.

"Considerando a paisagem como o fato que melhor expressava o relacionamento entre o homem e o meio e caracterizava as diferenças entre as áreas, mostrando concreta e objetivamente os diversos acontecimentos, a função do geógrafo era a de pesquisar a natureza visível, os elementos da fisionomia." (CHRISTOFOLETTI, 1982, p.71)

Num segundo momento, a geografia começou a incorporar ao conceito de paisagem uma visão mais humanística.

"Os estudos da paisagem, inicialmente muito focados na descrição das formas físicas da superfície terrestre, foram progressivamente incorporando os dados da transformação humana do ambiente no tempo, com a individualização das paisagens culturais face às paisagens naturais, sem nunca perder de vista as interligações mútuas" (SALGUEIRO, p. 41, 2001)

A passagem acima citada refere-se provavelmente a uma nova ruptura epistemológica, tanto vivenciada pela ciência como pela geografia. Na ciência, esse talvez seja o momento da ruptura epistemológica entre ciência moderna, totalmente positivista e quantificável, e ciência pós-moderna, que retoma alguns princípios da ciência clássica, numa certa possibilidade do subjetivo também ser ciência. Quantificar não necessariamente é o caminho para se fazer ciência com qualidade, começa-se a questionar nesse período.

Já para a Geografia, este momento em que a interação homem-meio começa a ser analisada é a saída de uma Geografia também quantitativa rumo a Geografia Crítica, onde ao conceito de paisagem finalmente vai ser somada as interações do ser humano com seu meio. No início dos anos 70 a insatisfação perante o paradigma quantitativo começa a questionar seus resultados e o sentimento de descontentação se converteu então em um movimento crítico radical (CAPEL, 1981, p. 426).

Antes da Geografia Crítica (do movimento radical) a transformação da paisagem é estudada como mero processo 
KIYOTANI, I. O conceito de paisagem no tempo.

evolutivo, sem serem avaliadas as causas dessa. Era como se a justificativa para as transformações fosse a simples passagem natural do tempo (cronológico), desconsiderando inclusive o poder de impacto da cultura humana sobre as paisagens. No entanto, com a visão crítica, começa-se a questionar os problemas sociais que estão por trás e que realmente justificam boa parte das transformações na paisagem.

Com a paisagem sendo entendida como o resultado de uma interação homem-meio, possibilitando enxergar o homem como construtor e transformador de paisagem, muito do que foi escrito antes sobre este conceito já não fazia muito sentido. Analisar a paisagem como mera "evolução" da natureza não proporcionava entendimento nem solucionava muitos problemas que envolviam este tema. Era preciso mudar, rever conceitos. A percepção sobre a paisagem começou a ganhar consistência e a explicar melhor o que estava à frente e por trás de nossa visão. Em 1990, Troppmair escreveu,

"Apesar de criticada como imprecisa, a palavra paisagem é hoje, novamente usada pelos cientistas face a visão da natureza como um 'Todo', como um sistema, que ela dá. Sauer em 1925 afirma: 'paisagem é uma unidade espacial de fenômenos interdependentes'. Bertrand, 1972 diz: paisagem não é uma simples adição de elementos geográficos disparatados. É numa determinada porção do espaço, o resultado da combinação dinâmica, portanto instável, de elementos físicos, biológicos e antrópicos, que reagindo dialeticamente uns sobre os outros, fazem da paisagem um conjunto único e indissociável, em perpétua evolução" (TROPPMAIR, 1990, p. 33)

Portanto é notável, através dessa passagem, como a acepção da paisagem entre os geógrafos muda da década de 20 para a de 70 . A geografia admitiu que paisagem não poderia ser entendida nem explicada sem a presença do ser humano em seu conceito. $\mathrm{O}$ homem como seu principal transformador é agora elemento ativo desta paisagem. A Geografia Humana designou o terno paisagem 
KIYOTANI, I. O conceito de paisagem no tempo.

cultural para definir aquela paisagem totalmente antropizada que, com o advento do capitalismo, começava a se sobrepor a paisagem natural.

Com a mudança do ponto de vista do que constitui uma paisagem, o questionamento de como ela é vista e percebida começa a mudar também. Como a paisagem já não é algo que se possa mais debulhar meramente em elementos físicos, a percepção também começa a aguçar os sentidos e sentimentos do observador, afinal não há como avaliar ou descrever uma paisagem sem vê-la por dentro.

"A paisagem é definida a partir do ponto de vista de onde ela é observada: isto supõe, como sua própria condição de existência, a atividade constituinte de um sujeito. (...) A paisagem não é objeto autônomo em si face do qual o sujeito poderia se situar em uma relação de exterioridade; ela se revela numa experiência em que o sujeito e objeto são inseparáveis, não somente porque o objeto espacial é constituído pelo sujeito, mas também porque o sujeito, por sua vez, aí se acha envolvido pelo espaço". (COLLOT, 1990, p. 22)

Em um breve, porém consistente trabalho, Michel Collot (1990) faz uma série de consideração sobre a percepção da paisagem que falam sobre essa relação totalmente imparcial entre observador e objeto (paisagem); duas passagens chamam atenção:

"Por não se deixar observar totalmente, é que a paisagem se constitui como totalidade coerente; ela forma um todo, alcançado de um só golpe (...) Essa coerência, essa convergência de seus elementos constitutivos torna também a paisagem apta a significar: ela se apresenta com uma unidade de sentidos, ela fala a quem olha". (COLLOT, 1990, p.24)

"A ação de ver (do observador) não se limita a registrar o fluxo de dados sensoriais; ela os organiza e interpreta, de maneira a fazer dele uma mensagem" (COLLOT, 1990, p.25). 
KIYOTANI, I. O conceito de paisagem no tempo.

$\mathrm{O}$ que estas duas passagens têm a dizer é justamente que o observador não é um "personagem" inerte, sem sentimentos e sensações; o seu eu subjetivo vai fazer parte dessa leitura, bem como a paisagem se constitui de elementos que tem seu significado. Assim é fácil compreender que cada observador vai fazer sua própria leitura de cada paisagem.

Marenzi (2003) em um breve artigo sobre a percepção da paisagem elenca o discurso de diversos autores sobre o tema, concentrando-se naqueles das décadas de 80 e 90 . Pode-se inferir deste trabalho que os autores enfocam o subjetivismo na percepção da paisagem, o que leva a admissão de uma lógica (opinião) muito individual na avaliação da "qualidade da paisagem", pois como apresentam os autores, o subjetivismo constitui-se em uma forma de analisar que vem sendo construída desde a infância, é a cultura e a educação que se acumula e se transforma/molda com o passar dos anos.

Dentro desse estudo de Marenzi (2003), chama a atenção uma interpretação que a autora faz do trabalho de Jordana (1992) quando diz: a percepção da paisagem, a partir de estímulos recebidos do meio, é um ato criativo, condicionado a fatores inerentes ao próprio individuo, a fatores educativos e culturais e a fatores emotivos, afetivos e sensitivos.

Dois observadores provavelmente não avaliarão uma mesma paisagem da mesma forma, principalmente se eles forem de campos distintos do conhecimento. Por exemplo, um geógrafo e um arquiteto não analisarão uma dada paisagem sob os mesmos elementos de análise, bem como terão objetivos diferentes ao olhar a paisagem o que fará com que os produtos dessa observação sejam bastante diferentes. Além dos campos de pesquisa e das metodologias diferentes, os observadores também carregam consigo realidades pessoais diferentes, maneiras diferentes de ver o mundo, concepções próprias de belo e feio e de qualidade. Enfim, mesmo que eles tenham uma mesma orientação científica é difícil que dois observadores construam uma visão igual de uma mesma paisagem. 
KIYOTANI, I. O conceito de paisagem no tempo.

Concepções mais contemporâneas trazem algumas conceituações da paisagem para a ciência hoje, segundo Mateo Rodriguez $^{4}$ (2000), paisagem pode ser entendida como: "um sistema espacial o territorial, compuesto por elementos naturales y antropo-tecnogénicos condicionados socialmente, los cuales modifican o transforman las propriedades de los paisajes naturales originales"; "área o espacio donde vive la sociedad humana, que se caracteriza por um determinado patrón de relaciones espaciales, que tiene importância existencial para la sociedad"; e por fim, como "resultado de la acción de la cultura a lo largo del tiempo, siendo modelado por um grupo cultural a partir de um paisaje natural".

Essas associações de paisagem à cultura, tão evidenciadas acima, é a reflexão de um momento no tempo onde uma paisagem muito provavelmente vai ser formada por características do humano, da presença humana. Essa atual sociedade capitalista modificou o meio de uma forma que não se tem a capacidade de retorno às "paisagens naturais", aquelas preservadas, onde a natureza é o grande cenário. As culturas e formas de vida em sociedade estão intrínsecas, indissociáveis, à paisagem, ao visível e principalmente invisível do hoje.

Outra ideia transcrita por Mateo Rodriguez é a de paisagem como sistema ou de que paisagem espelha o sistema. Essa abordagem sistêmica da paisagem crescerá com o surgimento da biogeografia, uma área que une dois conhecimentos, o da geografia e o da ecologia. Tricard (1982, p. 472) ${ }^{5}$ discorrendo sobre biogeografia diz que suas "investigaciones tienen um objeto espacial, pero solo pueden explicarlo basándose em las relaciones de los seres vivos y su médio, es dicir, em la ecologia”. Assim, na

${ }^{4}$ MATEO-RODRIGUEZ, José Manuel. Geografía de los Paisajes. La Habana: Unibversidad de La Habana, 2000. Citado por ROCHA, 2008.

${ }^{5}$ TRICARD, Jean. EI Analisis de Sistemas y El Estúdio Integrado del Médio Natural. In: CHRISTOFOLETTI, Antonio (org). Perspectivas da Geografia. São Paulo: Difel, 1982. 
KIYOTANI, I. O conceito de paisagem no tempo.

biogeografia a paisagem toma lugar importante na analise dos sistemas bióticos e abióticos e suas interações antrópicas que compõem o meio.

Salgueiro (2001, p. 44) complementa o raciocínio: “o desenvolvimento da biogeografia e de alguns aspectos da geomorfologia mais próximos da ecologia estão na base de uma 'ciência da paisagem' de caráter ecológico e profundamente naturalista (...) que, em termos metodológicos se aproximam da teoria dos sistemas". Como sistema a paisagem começa a ser entendida por completo à medida que reflete e é reflexo das várias relações sociais e homem-meio existentes e que podem ser visualizadas e estudadas através da paisagem.

Neste ponto, há de se enfatizar a paisagem como categoria de análise geográfica, que justamente lhe dá status de sustentáculo da ciência. Mas alguns autores divergem dessa colocação. Suertegaray (2001), por exemplo, considera que paisagem é mais um conceito operacional que uma categoria analítica, pois possibilita a leitura do espaço geográfico (este sim categoria). Portanto paisagem para esta autora delineia um caminho metodológico.

Baseado no trabalho da autora acima citada tem-se uma sucinta diferenciação entre paisagem e espaço. Paisagem é percebida pelos geógrafos como a expressão materializada das relações do homem com o seu meio (num recorte do espaço). Mas esse conceito vai além do visual, porque paisagem é processo, interação entre diferentes elementos do meio e é passível do tempo. Para Santos (1997) ${ }^{6}$, "paisagem é o conjunto de formas que, num dado momento, exprimem a herança que representam as sucessivas relações localizadas entre o homem e a natureza".

${ }^{6}$ Obra citada por Suertergaray em seu respectivo artigo "Espaço Geográfico Uno e Múltiplo". Scripta Nova. REVISTA ELECTRÓNICA DE GEOGRAFÍA Y CIENCIAS SOCIALES. N ${ }^{\circ}$ 93. Barcelona - Espanha: Universidade de Barcelona, 2001. 
KIYOTANI, I. O conceito de paisagem no tempo.

Nessa perspectiva, paisagem difere de espaço: paisagem é transtemporal, uma construção transversal juntando objetos. Espaço é sempre um presente, uma construção horizontal. Como conceito operacional (proposto por Suertegaray), paisagem permite analisar o espaço sob uma dimensão,

"qual seja o da conjunção de elementos naturais e tecnificados, sócio-econômicos e culturais. Ao optarmos pela análise geográfica a partir do conceito de paisagem, poderemos concebê-la enquanto forma (formação) e funcionalidade (organização) (...) percebendo-a como um processo de constituição e reconstituição de formas na sua conjugação com a dinâmica social. Neste sentido, a paisagem pode ser analisada como a materialização das condições sociais de existência diacrônica e sincronicamente. Nela poderão persistir elementos naturais, embora já transfigurados (ou natureza artificializada). $\mathrm{O}$ conceito de paisagem privilegia a coexistência de objetos e ações sociais na sua face econômica e cultural manifesta" (SUERTEGARAY, 2001, p. 5)

Este pensamento da autora fecha uma série de questões aqui colocadas sobre o conceito de paisagem, pois ele resume as conotações que hoje podem ser empregadas ao termo, desde observações do dito natural, até observações econômicas e culturais.

\section{Considerações Finais}

A partir das ideias aqui exposta e diante de tantos trabalhos sobre o tema, pode-se notar o quanto paisagem é um conceito complexo e bastante trabalhado, seja pela geografia ou por outra ciência. O conceito de paisagem é utilizado por muitos campos do conhecimento além da geografia: arquitetura, ecologia, sociologia, artes, literatura, filosofia, engenharia, urbanismo. Esta é apenas uma pequena lista de onde este conceito pode ser encontrado, ou seja, mostra o quanto é importante a noção e percepção da paisagem para muitos. 
KIYOTANI, I. O conceito de paisagem no tempo.

Mas não é apenas para quem faz ciências que o conceito de paisagem torna-se importante, para todos nós este também é um conceito bastante presente, afinal paisagem esta no nosso dia-a-dia. Nas ruas, praças, praias, grandes avenidas, parques; no condomínio ao lado, nas montanhas distantes... O que nós vemos? E enfim, "tudo aquilo que a vista abarca" 7 não é mesmo paisagem!

Tudo que esta ao nosso redor compõe a paisagem, nós mesmos estamos dentro dela, nos fazemos presentes também com nossas culturas, impostas fisicamente ou não. O colorido ou a palidez das ruas, das roupas, vitrines, tudo isso esta na paisagem e vai contar aos observadores um pouco da cultura daquele povo.

A diferença entre um pesquisador e um não pesquisador ao ver a paisagem está apenas na forma que ele avaliará o seu objeto; uns utilizaram de metodologias mais imparciais para qualificá-lo, outros deixarão seus sentimento dizerem o que é feio e o que é belo.

\section{Referências bibliográficas}

ALVES, Teresa. Paisagem: em busca do lugar perdido. Revista Finisterra, ano XXXVI, vol. 72, p. 37-53. Lisboa, 2001.

CAPEL, Horácio. La quiebra del positivismo y Las geografias radicales. In: __ Filosofia y Ciência em la Geografia Comtemporanea: uma intruduccion a la geografia. Barcelona, Espanha: Baroanova, 1981.

CHRISTOFOLETTI, Antonio. As características da Nova Geografia. In:

Paulo: Difel, 1982. (org). Perspectivas da Geografia. São

${ }^{7}$ SANTOS, Milton. Metamorfose do Espaço Habitado: Fundamentos Teórico e metodológico da geografia. Hucitec. São Paulo 1988. 
KIYOTANI, I. O conceito de paisagem no tempo.

COLLOT, Michel. Pontos de vista sobre as percepções da paisagem. Boletim da Geografia Teorética, vol.20 (39); p: 21-32. Rio Claro: Unesp, 1990.

MARENZI, Rosemer Carvalho. Percepção da Paisagem. Univali, 2003. Disponível em: www.cehcom.univali.br/educacao.

ROCHA, Yuri Tavares. Paisagens Urbanas Brasileiras e a Teoria Geográfica da Paisagem. In: Carlos G. Terra \& Rubens de Andrade. (Org.). Paisagens culturais: contrastes sul-americanos. $1^{\mathrm{a} e d}$. Rio de Janeiro (RJ): Escola de Belas Artes/UFRJ, 2008, v. 1, p. 123-141.

ROSENDAHL, Z.; CORRÊA, R. (org). Paisagem, Imaginário e Espaço. Rio de Janeiro: Universidade Estadual do Rio de Janeiro, 2001.

SALGUEIRO, Teresa Barata. Paisagem e Geografia. Revista Finisterra, ano XXXVI, vol. 72, p. 37-53. Lisboa, 2001.

SANTOS, Boaventura de Sousa. Ciência e Senso Comum. In:__ Introdução a uma ciência Pós-moderna. Porto: Litografia Ach Brito, 1989.

SUERTEGARY, Dirce Maria Antunes. Espaço Geográfico Uno e Múltiplo. Scripta Nova Revista Electrónica de Geografía y Ciencias Sociales. $n^{\circ}$ 93. Barcelona - Espanha: Universidade de Barcelona, 2001.

TRICART, Jean. Paisagem e Ecologia. Revista Inter-Facies: escritos e documentos. No76. P. 1-54. São José do Rio Preto: Unesp, 1982. 
KIYOTANI, I. O conceito de paisagem no tempo.

$\overline{\text { Médio }}_{\text {Natural. In: CHRISTOFOLETTI, Antonio (org). }}$ Perspectivas da Geografia. São Paulo: Difel, 1982.

TROPPMAIR, Helmut. Geomorfologia e Ecologia. Boletim da Geografia Teorética, vol.20 (39); p: 33-44. Rio Claro: Unesp, 1990.

Recebido em agosto de 2013

Aceito em maio de 2014 